\title{
MALDI-TOF Mass Spectrometric Identification of Dyes and Pigments
}

\author{
L. J. Soltzberg, a Amanda Hagar, ' Supicha Kridaratikorn, ${ }^{\text {a }}$ \\ Anne Mattson, ${ }^{\mathrm{a}}$ and Richard Newman ${ }^{\mathrm{b}}$ \\ ${ }^{a}$ Department of Chemistry, Simmons College, Boston, Massachusetts, USA \\ b Scientific Research Laboratory, Museum of Fine Arts, Boston, Massachusetts, USA
}

We have used MALDI-TOF mass spectrometry to characterize a selection of dyes from the Schweppe dye collection and pigments from the Tate Gallery collection. MALDI-TOF mass spectra of such samples are easily obtained and, through observation of both positive and negative ion spectra, provide a convenient, versatile method for dye characterization and identification. Such pairs of positive and negative ion spectra immediately distinguish between acidic and basic dyes and provide the characteristic mass of either the molecular ion or a simply related fragment ion. This approach is especially useful in situations where very small amounts of analyte are available, as in museum research and forensic analysis. In the case of textile dyes, we have carried out identification on material from single fibers and, with insoluble pigments, have begun to identify components of historically important pastel sticks from submicrogram samples. (J Am Soc Mass Spectrom 2007, 18, 2001-2006) (c) 2007 American Society for Mass Spectrometry

$\mathrm{T}$ The special advantages of matrix assisted laser desorption ionization time of flight (MALDITOF) mass spectrometry have been applied principally to large molecules, such as synthetic polymers, proteins, and nucleic acids. However, there have been some notable applications of this mass spectrometric method to small molecule analytes [1, 2]. Simplicity of sample preparation, rapid spectrum acquisition, high sensitivity, and relative tolerance to impurities make MALDI-TOF attractive here. Direct laser desorption ionization (LDI) mass spectrometry, with no matrix, has also been explored for the investigation of inks and dyes [3, 4].

We assess here the utility of MALDI-TOF mass spectrometry for the identification of dyes and pigments from standard collections; the molecular masses of these substances are in the 200 to $1100 \mathrm{Da}$ range. Application of the new solvent-free vortex grinding method for sample preparation $[5,6]$ is well suited for the small sample sizes available in this work and is also assessed.

\section{Experimental}

\section{Sample Preparation}

We have utilized both a traditional overlay method and the new solvent-free vortex grinding method. In the

Address reprint requests to Dr. L. J. Soltzberg, Department of Chemistry, Simmons College, 300 The Fenway, Boston, MA 02115, USA. E-mail: leonard.soltzberg@simmons.edu overlay method, $4 \mu \mathrm{L}$ of a saturated methanol solution of 9-aminoacridine (9AA) matrix (Aldrich S517216) was deposited on the stainless steel target and allowed to air dry. One $\mu \mathrm{L}$ of methanolic dye solution from the Schweppe collection [7] was then applied near the edge of the matrix spot.

For the solvent-free method of Hanton and Parees [5], the sample and matrix were intimately ground in a $4 \mathrm{~mL}$ glass vial containing two $4.5 \mathrm{~mm}$ diameter zinc-plated steel balls using a vortex mixer. For dyes, we applied $1 \mu \mathrm{L}$ of the dye solution to about $15 \mathrm{mg}$ of dry 9AA matrix in the vial, evaporated the methanol under vacuum, scraped the vial walls with a spatula to free the solid deposit, and proceeded with the vortex grinding. For insoluble pigments, about $15 \mathrm{mg}$ of 9AA matrix was added to a microcentrifuge tube containing a barely visible amount of pigment dust $(\sim 0.5 \mu \mathrm{g})$ and mixed with a spatula; this mixture was then transferred to the $4 \mathrm{~mL}$ glass vial with the metal balls for vortex grinding.

For textile samples, a few fibers were hydrolyzed for $15 \mathrm{~min}$ at $90{ }^{\circ} \mathrm{C}$ in a solution composed of $37 \% \mathrm{HCl}$ : methanol:water, 1:1:2 (vol/vol/vol), followed by drying under vacuum. The hydrolyzed material was then dissolved in about $150 \mu \mathrm{L}$ of methanol/water (1:1 vol:vol). One $\mu \mathrm{L}$ of this solution was applied to the MALDI target as described above.

The 9AA matrix (nominal mass $194 \mathrm{Da}$ ) produces negative ion peaks at $\mathrm{m} / \mathrm{z} 193.5$ [9AA $-\mathrm{H}]^{-}$and 387.2 $\left[9 \mathrm{AA}_{2}-\mathrm{H}\right]^{-}$and (for chloride containing dyes) $\mathrm{m} / \mathrm{z}$ $229.4[9 \mathrm{AA}+\mathrm{Cl}]^{-}$; and positive ion peaks at $\mathrm{m} / \mathrm{z} 194.7$ 
$[9 \mathrm{AA}+\mathrm{H}]^{+}$and $389.1\left[9 \mathrm{AA}_{2}+\mathrm{H}\right]^{+}$and (for sodium containing dyes) $m / z 216.8\left[9 \mathrm{AA}+\mathrm{Na}^{+}\right.$and 411.1 $\left[9 \mathrm{AA}_{2}+\mathrm{Na}\right]^{+}$; therefore, care must be taken not to mistake these peaks for analyte signals.

Negative ion spectra were calibrated using the [M $\mathrm{H}]^{-}$peaks from picric acid (Aldrich 239801, St. Louis, MO) and erythrosin B (Sigma E9259, St. Louis, MO) as external standards. Positive ion spectra were calibrated with positive cesium iodide clusters $\mathrm{Cs}_{2} \mathrm{I}^{+}$and $\mathrm{Cs}_{3} \mathrm{I}_{2}{ }^{+}$.

Spectra for assessing precision and accuracy were run with mordant yellow 1 (sold as Alizarin Yellow GG; Aldrich 206709).

\section{Instrumentation}

We used a Bruker Omniflex benchtop MALDI-TOF mass spectrometer equipped with a $337 \mathrm{~nm}$ nitrogen laser. Laser power was set at around $150 \mu \mathrm{J}$, about $5 \mu \mathrm{J}$ above the threshold for appearance of ions. Pulsed ion extraction was employed, with an extraction delay of 300 ns. Both positive and negative ion spectra for each dye were run in reflectron mode at the same laser power. The accelerating potential was $14.8 \mathrm{kV}$ for positive ion spectra and $15.8 \mathrm{kV}$ for negative ion spectra. Each spectrum was the average of 50 laser shots. Spectra were analyzed using Bruker XMass version 6.0.0 software (Billerica, MA).

\section{Results and Discussion}

Tables 1 and 2 summarize negative- and positive-ion spectra (respectively) for 57 of the 66 dyes in the Schweppe collection [7]. We have omitted nine samples from the tables either because of obvious decomposition or because the library samples appear to be mislabeled, based on mass spectral comparison with newly purchased dyes of positive identity. The base peak data for each dye are listed with negative- or positive-ion spectra, depending on which instrument polarity shows the strongest signal, as described above. Having this information about an unknown dye sample would be an important aid in identification. For certain dyes in these tables, multiple peaks are listed with their relative intensities shown in parentheses.

\section{Anionic Versus Cationic Dyes}

For acid orange 20 (Table 1 ), a representative anionic dye, the negative ion base peak at $m / z 327.4[\mathrm{M}-\mathrm{Na}]^{-}$has an intensity approximately five times greater than the largest peak in the positive ion spectrum, which is a matrix peak. Acid dyes are usually encountered as sodium salts of sulfonic acids, so the abundance of anions is expected. Certain other dyes, such as mordant red 11 (commonly called "alizarin"), are not salts but form resonancestabilized anions and, thus, are apparently deprotonated in the MALDI plume (Table 1). For basic yellow 2 (Table $2)$, a typical cationic dye, the situation is reversed. Here, the positive ion base peak at $m / z 268.0[\mathrm{M}-\mathrm{Cl}]^{+}$is about ten times as intense as the negative ion base peak, which is a matrix peak. Basic dyes are typically hydrochloride salts, so formation of cations by loss of $\mathrm{Cl}^{-}$is reasonable. Although the 9AA matrix was originally promoted for generating negative ion MALDI spectra (in contrast with the much more common protonating matrices) [8], we have found that 9AA produces abundant analyte ions for both anionic acid dyes and cationic basic dyes, with the mass spectrometer operating in negative ion and positive ion mode, respectively.

Thus, the comparison of the intensity of negative and positive ion spectra for a particular dye allows the quick classification of the dye as acid or basic. Such a comparison has also been exploited for analysis of inks by electrospray ionization-TOF mass spectrometry [9].

\section{Pigments Versus Dyes}

Solvent-free methods $[5,6]$ eliminate solvent requirements for sample preparation through intimate grinding of the solid analyte with the solid matrix, followed by application of a thin powder film on the target. For insoluble analytes, such as pigments, the solvent-free method is mandatory. Figure 1 illustrates the quality of a pigment red 166 spectrum $\left([\mathrm{M}+\mathrm{Na}]^{+}\right.$for $\mathrm{M}=$ $\mathrm{C}_{40} \mathrm{H}_{24} \mathrm{Cl}_{4} \mathrm{~N}_{6} \mathrm{O}_{4}$ ) obtained by the solvent-free vortex grinding method. The spectra from the solvent-free sample preparation are excellent and, when both methods are feasible, are less prone to the MALDI "sweet spot" phenomenon than samples deposited from solution, making it easier to obtain high quality spectra.

Preliminary work applying the solvent-free preparation to "real" solid samples is encouraging. Figure 2a shows the positive ion spectrum of a sample prepared from dust harvested from a red pastel stick belonging to late 19th/early 20th century artist Mary Cassatt [10]. The strong peak at $m / z 443.2$ is consistent with the presence of rhodamine B. The peaks at $m / z 389.1$ and 411.1 are matrix peaks. A detailed study of these materials is underway in our laboratories.

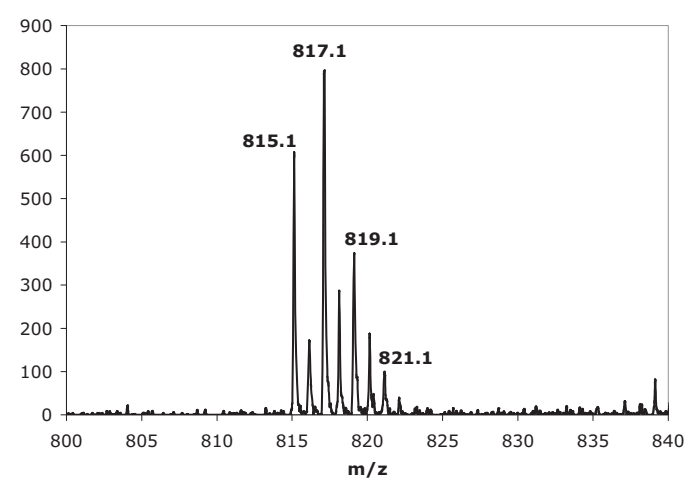

Figure 1. Positive ion spectrum of Pigment Red 166 from solvent-free vortex grinding method. 
Table 1. Dyes from the Schweppe collection [7] showing stronger negative ion mass spectra

\begin{tabular}{|c|c|c|c|c|}
\hline Dye & $\mathrm{Cl}$ number & Formula & Species observed & Observed mass \\
\hline Picric acid & 10305 & $\mathrm{C}_{6} \mathrm{H}_{3} \mathrm{~N}_{3} \mathrm{O}_{7}$ & {$[\mathrm{M}-\mathrm{H}]^{-}$} & 228.4 \\
\hline Acid yellow 24 & 10315 & $\mathrm{C}_{10} \mathrm{H}_{5} \mathrm{~N}_{2} \mathrm{O}_{5} \mathrm{Na}$ & {$[\mathrm{M}-\mathrm{Na}]^{-}$} & 233.1 \\
\hline Acid yellow 1 & 10316 & $\mathrm{C}_{10} \mathrm{H}_{4} \mathrm{~N}_{2} \mathrm{SO}_{8} \mathrm{Na}_{2}$ & {$[\mathrm{M}-2 \mathrm{Na}+\mathrm{H}]^{-}$} & 313.1 \\
\hline Acid yellow 36 & 13065 & $\mathrm{C}_{18} \mathrm{H}_{14} \mathrm{~N}_{3} \mathrm{SO}_{3} \mathrm{Na}$ & {$[\mathrm{M}-\mathrm{Na}]^{-}$} & 352.5 \\
\hline Acid orange 5 & 13080 & $\mathrm{C}_{18} \mathrm{H}_{14} \mathrm{~N}_{3} \mathrm{SO}_{3} \mathrm{Na}$ & {$[\mathrm{M}-\mathrm{Na}]^{-}$} & 352.2 \\
\hline Acid red 74 & 13355 & $\mathrm{C}_{16} \mathrm{H}_{11} \mathrm{~N}_{4} \mathrm{SO}_{5} \mathrm{Na}$ & {$[\mathrm{M}-\mathrm{Na}]^{-}$} & 371.1 \\
\hline Mordant yellow 1 & 14025 & $\mathrm{C}_{13} \mathrm{H}_{8} \mathrm{~N}_{3} \mathrm{O}_{5} \mathrm{Na}$ & {$[\mathrm{M}-\mathrm{Na}]^{-}$} & 286.1 \\
\hline Acid orange 6 & 14270 & $\mathrm{C}_{12} \mathrm{H}_{9} \mathrm{~N}_{2} \mathrm{SO}_{5} \mathrm{Na}$ & {$[\mathrm{M}-\mathrm{Na}]^{-}$} & 293.4 \\
\hline \multirow[t]{2}{*}{ Acid orange 20} & 14600 & $\mathrm{C}_{16} \mathrm{H}_{11} \mathrm{~N}_{2} \mathrm{SO}_{4} \mathrm{Na}$ & {$[\mathrm{M}-\mathrm{Na}]^{-}$} & $327.4(100)$ \\
\hline & & & Minor peak & $407.1(18)$ \\
\hline Acid brown 6 & 14625 & $\mathrm{C}_{20} \mathrm{H}_{13} \mathrm{~N}_{2} \mathrm{SO}_{4} \mathrm{Na}$ & {$[\mathrm{M}-\mathrm{Na}]^{-}$} & 377.2 \\
\hline \multirow[t]{5}{*}{ Acid orange 7} & 15510 & $\mathrm{C}_{16} \mathrm{H}_{11} \mathrm{~N}_{2} \mathrm{SO}_{4} \mathrm{Na}$ & {$[\mathrm{M}-\mathrm{Na}]^{-}$} & $327.1(100)$ \\
\hline & & & Minor peak & $341.0(22)$ \\
\hline & & & Minor peak & $406.8(10)$ \\
\hline & & & Minor peak & $675.9(22)$ \\
\hline & & & Minor peak & $689.8(7)$ \\
\hline Acid red 88 & 15620 & $\mathrm{C}_{20} \mathrm{H}_{13} \mathrm{~N}_{2} \mathrm{SO}_{4} \mathrm{Na}$ & {$[\mathrm{M}-\mathrm{Na}]^{-}$} & 376.9 \\
\hline Acid red 9 & 15635 & $\mathrm{C}_{20} \mathrm{H}_{13} \mathrm{~N}_{2} \mathrm{SO}_{4} \mathrm{Na}$ & {$[\mathrm{M}-\mathrm{Na}]^{-}$} & 377.2 \\
\hline \multirow[t]{3}{*}{ Acid orange 12} & 15970 & $\mathrm{C}_{16} \mathrm{H}_{11} \mathrm{~N}_{2} \mathrm{SO}_{4} \mathrm{Na}$ & {$[\mathrm{M}-\mathrm{Na}]^{-}$} & $327.3(100)$ \\
\hline & & & Minor peak & $585.5(13)$ \\
\hline & & & Minor peak & $676.1(45)$ \\
\hline \multirow[t]{2}{*}{ Acid red 13} & 16045 & $\mathrm{C}_{20} \mathrm{H}_{12} \mathrm{~N}_{2} \mathrm{~S}_{2} \mathrm{O}_{7} \mathrm{Na}_{2}$ & {$[\mathrm{M}-\mathrm{Na}]^{-}$} & $479.0(14)$ \\
\hline & & & {$[\mathrm{M}-2 \mathrm{Na}+\mathrm{H}]^{-}$} & $457.1(100)$ \\
\hline \multirow[t]{2}{*}{ Acid red 25} & 16050 & $\mathrm{C}_{20} \mathrm{H}_{12} \mathrm{~N}_{2} \mathrm{~S}_{2} \mathrm{O}_{7} \mathrm{Na}_{2}$ & {$[\mathrm{M}-\mathrm{Na}]^{-}$} & $479.0(100)$ \\
\hline & & & {$[\mathrm{M}-2 \mathrm{Na}+\mathrm{H}]^{-}$} & $457.1(44)$ \\
\hline Acid orange 14 & 16100 & $\mathrm{C}_{16} \mathrm{H}_{10} \mathrm{~N}_{2} \mathrm{~S}_{2} \mathrm{O}_{7} \mathrm{Na}_{2}$ & {$\left[\mathrm{M}-2 \mathrm{Na}-\mathrm{SO}_{3}+\mathrm{H}\right]^{-}$} & 327.1 \\
\hline Acid red 26 & 16150 & $\mathrm{C}_{18} \mathrm{H}_{14} \mathrm{~N}_{2} \mathrm{~S}_{2} \mathrm{O}_{7} \mathrm{Na}_{2}$ & {$[\mathrm{M}-2 \mathrm{Na}+\mathrm{H}]^{-}$} & 434.8 \\
\hline Acid red 17 & 16180 & $\mathrm{C}_{20} \mathrm{H}_{12} \mathrm{~N}_{2} \mathrm{~S}_{2} \mathrm{O}_{7} \mathrm{Na}_{2}$ & {$[\mathrm{M}-2 \mathrm{Na}+\mathrm{H}]^{-}$} & 456.7 \\
\hline Acid red 27 & 16185 & $\mathrm{C}_{20} \mathrm{H}_{11} \mathrm{~N}_{2} \mathrm{~S}_{3} \mathrm{O}_{10} \mathrm{Na}_{3}$ & {$\left[\mathrm{M}-3 \mathrm{Na}-2 \mathrm{SO}_{3}+2 \mathrm{H}\right]^{-}$} & 377.3 \\
\hline \multirow[t]{2}{*}{ Acid orange 10} & 16230 & $\mathrm{C}_{16} \mathrm{H}_{10} \mathrm{~N}_{2} \mathrm{~S}_{2} \mathrm{O}_{7} \mathrm{Na}_{2}$ & {$[\mathrm{M}-\mathrm{Na}]^{-}$} & $429.0(29)$ \\
\hline & & & {$[\mathrm{M}-2 \mathrm{Na}+\mathrm{H}]^{-}$} & $407.1(100)$ \\
\hline Acid red 44 & 16250 & $\mathrm{C}_{20} \mathrm{H}_{12} \mathrm{~N}_{2} \mathrm{~S}_{2} \mathrm{O}_{7} \mathrm{Na}_{2}$ & {$[\mathrm{M}-2 \mathrm{Na}+\mathrm{H}]^{-}$} & 457.1 \\
\hline Acid red 18 & 16255 & $\mathrm{C}_{20} \mathrm{H}_{11} \mathrm{~N}_{2} \mathrm{~S}_{3} \mathrm{O}_{10} \mathrm{Na}_{3}$ & {$[\mathrm{M}-3 \mathrm{Na}+2 \mathrm{H}]^{-}$} & 536.7 \\
\hline Acid red 41 & 16290 & $\mathrm{C}_{20} \mathrm{H}_{10} \mathrm{~N}_{2} \mathrm{~S}_{4} \mathrm{O}_{13} \mathrm{Na}_{4}$ & {$[\mathrm{M}-4 \mathrm{Na}+3 \mathrm{H}]^{-}$} & 617.4 \\
\hline Acid red 33 & 17200 & $\mathrm{C}_{16} \mathrm{H}_{11} \mathrm{~N}_{3} \mathrm{~S}_{2} \mathrm{O}_{7} \mathrm{Na}_{2}$ & {$[\mathrm{M}-2 \mathrm{Na}+\mathrm{H}]^{-}$} & 422.2 \\
\hline Acid red 1 & 18050 & $\mathrm{C}_{18} \mathrm{H}_{13} \mathrm{~N}_{3} \mathrm{~S}_{2} \mathrm{O}_{8} \mathrm{Na}_{2}$ & {$[\mathrm{M}-2 \mathrm{Na}+\mathrm{H}]^{-}$} & 464.0 \\
\hline Acid violet 7 & 18055 & $\mathrm{C}_{20} \mathrm{H}_{16} \mathrm{~N}_{4} \mathrm{~S}_{2} \mathrm{O}_{9} \mathrm{Na}_{2}$ & {$[\mathrm{M}-2 \mathrm{Na}+\mathrm{H}]^{-}$} & 520.9 \\
\hline Acid yellow 23 & 19140 & $\mathrm{C}_{16} \mathrm{H}_{9} \mathrm{~N}_{4} \mathrm{~S}_{2} \mathrm{O}_{9} \mathrm{Na}_{3}$ & {$[\mathrm{M}-3 \mathrm{Na}+2 \mathrm{H}]^{-}$} & 467.0 \\
\hline Acid black 1 & 20470 & $\mathrm{C}_{22} \mathrm{H}_{14} \mathrm{~N}_{6} \mathrm{~S}_{2} \mathrm{O}_{9} \mathrm{Na}_{2}$ & {$[\mathrm{M}-2 \mathrm{Na}+\mathrm{H}]^{-}$} & 571.0 \\
\hline Direct red 28 & 22120 & $\mathrm{C}_{32} \mathrm{H}_{22} \mathrm{~N}_{6} \mathrm{~S}_{2} \mathrm{O}_{6} \mathrm{Na}_{2}$ & {$[\mathrm{M}-2 \mathrm{Na}+\mathrm{H}]^{-}$} & 650.3 \\
\hline Direct yellow 4 & 24890 & $\mathrm{C}_{26} \mathrm{H}_{18} \mathrm{~N}_{4} \mathrm{~S}_{2} \mathrm{O}_{8} \mathrm{Na}_{2}$ & {$[\mathrm{M}-2 \mathrm{Na}+\mathrm{H}]^{-}$} & 578.9 \\
\hline Acid red 151 & 26900 & $\mathrm{C}_{22} \mathrm{H}_{15} \mathrm{~N}_{4} \mathrm{SO}_{4} \mathrm{Na}$ & {$[\mathrm{M}-\mathrm{Na}]^{-}$} & 430.9 \\
\hline Acid red 115 & 27200 & $\mathrm{C}_{24} \mathrm{H}_{18} \mathrm{~N}_{4} \mathrm{~S}_{2} \mathrm{O}_{7} \mathrm{Na}_{2}$ & {$[\mathrm{M}-2 \mathrm{Na}+\mathrm{H}]^{-}$} & 538.5 \\
\hline Acid red 73 & 27290 & $\mathrm{C}_{22} \mathrm{H}_{14} \mathrm{~N}_{4} \mathrm{~S}_{2} \mathrm{O}_{7} \mathrm{Na}_{2}$ & {$[\mathrm{M}-2 \mathrm{Na}+\mathrm{H}]^{-}$} & 511.0 \\
\hline Acid blue 3 & 42051 & $\mathrm{C}_{27} \mathrm{H}_{31} \mathrm{~N}_{2} \mathrm{~S}_{2} \mathrm{O}_{7} \mathrm{Na}$ & {$[\mathrm{M}-\mathrm{Na}]^{-}$} & 559.4 \\
\hline Acid green 5 & 42095 & $\mathrm{C}_{37} \mathrm{H}_{34} \mathrm{~N}_{2} \mathrm{~S}_{3} \mathrm{O}_{9} \mathrm{Na}_{2}$ & {$\left[\mathrm{M}-2 \mathrm{SO}_{3} \mathrm{Na}-\mathrm{CH}_{3}\right]^{-}$} & 570.7 \\
\hline Acid yellow 73 & 45350 & $\mathrm{C}_{20} \mathrm{H}_{12} \mathrm{O}_{5}$ & {$[\mathrm{M}-\mathrm{H}]^{-}$} & 331.4 \\
\hline Acid red 87 & 45380 & $\mathrm{C}_{20} \mathrm{H}_{6} \mathrm{O}_{5} \mathrm{Br}_{4} \mathrm{Na}_{2}$ & {$[\mathrm{M}-2 \mathrm{Na}+\mathrm{H}]^{-}$} & 642.5 \\
\hline Acid red 51 & 45430 & $\mathrm{C}_{20} \mathrm{H}_{6} \mathrm{O}_{5} \mathrm{I}_{4} \mathrm{Na}_{2}$ & {$\left[\mathrm{M}-2 \mathrm{Na}+\mathrm{H}^{-}\right.$} & 834.5 \\
\hline Acid yellow 3 & 47005 & $\mathrm{C}_{18} \mathrm{H}_{8} \mathrm{NS}_{3} \mathrm{O}_{11} \mathrm{Na}_{3}$ & {$\left[\mathrm{M}-3 \mathrm{Na}-2 \mathrm{SO}_{3}+2 \mathrm{H}\right]^{-}$} & 352.2 \\
\hline Murexide & 56085 & $\mathrm{C}_{8} \mathrm{H}_{8} \mathrm{~N}_{6} \mathrm{O}_{6}$ & {$\left[\mathrm{M}-\mathrm{NH}_{4}\right]^{-}$} & 266.0 \\
\hline Mordant red 11 & 58000 & $\mathrm{C}_{14} \mathrm{H}_{8} \mathrm{O}_{4}$ & {$[\mathrm{M}-\mathrm{H}]^{-}$} & 239.2 \\
\hline Alizarin red PS & 58219 & $\mathrm{C}_{14} \mathrm{H}_{8} \mathrm{SO}_{8}$ & {$\left[\mathrm{M}-\mathrm{SO}_{3}-\mathrm{H}\right]^{-}$} & 255.1 \\
\hline Mordant red 2 & 58260 & $\mathrm{C}_{14} \mathrm{H}_{7} \mathrm{SO}_{8} \mathrm{Na}$ & {$[\mathrm{M}-\mathrm{Na}]^{-}$} & 335.3 \\
\hline Acid blue $83^{a}$ & 42660 & $\mathrm{C}_{45} \mathrm{H}_{44} \mathrm{~N}_{3} \mathrm{~S}_{2} \mathrm{O}_{7} \mathrm{Na}$ & {$[\mathrm{M}-\mathrm{Na}]^{-}$} & 802.3 \\
\hline
\end{tabular}

( ) Specifies relative abundance when multiple peaks are present. aNot a Schweppe dye.

\section{Special Cases: Mixtures, Isomers, and Clusters}

In addition to their potential value as an identification aid for dyes and pigments, these data illustrate some points of interest regarding small molecule MALDITOF mass spectrometry.

Some dyes, even in their commercial form, are 
Table 2. Dyes from the Schweppe collection [7] showing stronger positive ion mass spectra

\begin{tabular}{lclll}
\hline \multicolumn{1}{c}{ Dye } & $\mathrm{Cl}$ number & \multicolumn{1}{c}{ Formula } & Species observed & Observed mass \\
\hline \hline Basic orange 2 & 11270 & $\mathrm{C}_{12} \mathrm{H}_{13} \mathrm{~N}_{4} \mathrm{Cl}$ & {$[\mathrm{M}-\mathrm{Cl}]^{+}$} & 212.7 \\
Basic brown 4 & 21010 & $\mathrm{C}_{21} \mathrm{H}_{26} \mathrm{~N}_{8} \mathrm{Cl}$ & {$[\mathrm{M}-2 \mathrm{Cl}-\mathrm{H}]^{+}$} & 389.2 \\
Basic yellow 2 & 41000 & $\mathrm{C}_{17} \mathrm{H}_{22} \mathrm{~N}_{3} \mathrm{Cl}$ & {$[\mathrm{M}-\mathrm{Cl}]^{+}$} & 268.0 \\
Basic green 4 & 42000 & $\mathrm{C}_{23} \mathrm{H}_{27} \mathrm{~N}_{2} \mathrm{OCl}$ & {$[\mathrm{M}-\mathrm{Cl}]^{+}$} & 345.1 \\
Basic green 1 & 42040 & $\mathrm{C}_{27} \mathrm{H}_{33} \mathrm{~N}_{2}$ & {$[\mathrm{M}] \bullet^{+}$} & 385.1 \\
Basic violet 14 & 42510 & $\mathrm{C}_{20} \mathrm{H}_{20} \mathrm{~N}_{3} \mathrm{Cl}$ & {$[\mathrm{Cl}]^{+}$} & 302.0 \\
Basic violet 3 & 42555 & $\mathrm{C}_{25} \mathrm{H}_{30} \mathrm{~N}_{3} \mathrm{Cl}$ & {$[\mathrm{Cl}]^{+}$} & 372.1 \\
Basic blue 11 & 44040 & $\mathrm{C}_{29} \mathrm{H}_{32} \mathrm{~N}_{3} \mathrm{Cl}$ & {$[\mathrm{Cl}]^{+}$} & 421.7 \\
Basic blue 26 & 44045 & $\mathrm{C}_{33} \mathrm{H}_{32} \mathrm{~N}_{3} \mathrm{Cl}$ & {$[\mathrm{M}]^{+}$} & 470.2 \\
Basic red 1 & 45160 & $\mathrm{C}_{28} \mathrm{H}_{31} \mathrm{~N}_{2} \mathrm{O}_{3} \mathrm{Cl}$ & {$[\mathrm{M}-\mathrm{Cl}]^{+}$} & 443.2 \\
Solvent red 49 & 45170 & $\mathrm{C}_{28} \mathrm{H}_{31} \mathrm{~N}_{2} \mathrm{O}_{3} \mathrm{Cl}$ & {$[\mathrm{M}-\mathrm{Cl}]^{+}$} & 343.2 \\
Basic red 2 & 50240 & $\mathrm{C}_{20} \mathrm{H}_{19} \mathrm{~N}_{4} \mathrm{Cl}$ & 315.0 \\
Basic blue 9 & 52015 & $\mathrm{C}_{16} \mathrm{H}_{18} \mathrm{~N}_{3} \mathrm{SCl}$ & {$[\mathrm{M}-\mathrm{Cl}]^{+}$} & 284.8 \\
\hline
\end{tabular}

mixtures of related compounds. Methyl violet (basic violet 1 ) and crystal violet (basic violet 3 ), used in ballpoint pen inks [3], are triphenylmethane dyes differing in the number of methyl groups; the Aldrich catalog lists methyl violet as a "mixture of polymethylated pararosaniline hydrochlorides" [11] and crystal violet as a "mixture of crystal violet and methyl violet" [12]. The MALDI-TOF mass spectrum of freshly prepared methyl violet shows peaks at $\mathrm{m} / \mathrm{z}$ $372.1,358.1,344.0$, and 330.0 corresponding to the hexamethyl, pentamethyl, tetramethyl, and trimethyl variants respectively. Also, aging of the ink results in demethylation of these molecules, which can be ob-
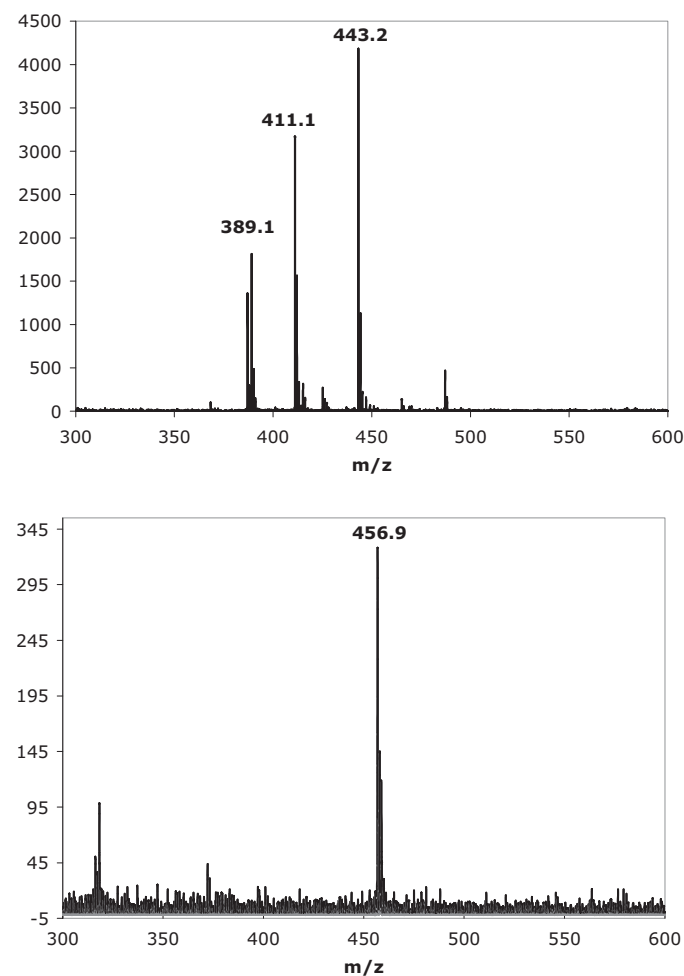

Figure 2. Spectra obtained from minute museum samples. (a) Positive ion spectrum of dust from red pastel stick belonging to Mary Cassatt. (b) Negative ion spectrum of extract from a few textile fibers from the Schweppe textile library. served in the MALDI-TOF mass spectra since each degradation product produces a molecular ion differing from its precursor by one methyl group. Grim et al. [3] have investigated the possibility that such spectra could be used to establish the age of a questioned document.

The fact that the MALDI ionization process produces relatively little fragmentation compared with other mass spectrometric ionization methods means that there is usually a strong molecular ion or a base peak ion closely related to the intact analyte molecule. This same characteristic, however, limits the utility of MALDI mass spectra for distinguishing between isomers. Nonetheless, there seem to be differences in the MALDI spectra of isomeric dyes that may be useful analytically. For example, as Table 1 shows, MALDI spectra of the Schweppe library samples of isomeric acid red 13 (Structure 1) and acid red 25 (Structure 2)

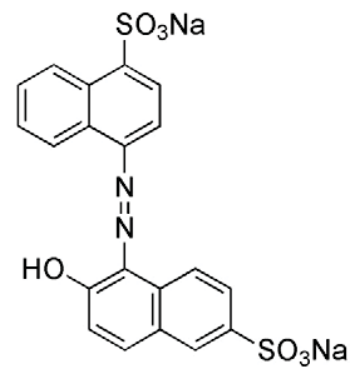

Structure 1<smiles>O=S(=O)(O)c1ccc(N=Nc2c(O)ccc3cccc(S(=O)(=O)O)c23)c2ccccc12</smiles>

Structure 2 
differ in that acid red 25 gives a strong $[\mathrm{M}-\mathrm{Na}]^{-}$peak at $m / z 479.0$ in addition to the $[\mathrm{M}-2 \mathrm{Na}+\mathrm{H}]^{-}$peak at $\mathrm{m} / \mathrm{z}$ 457.1; while acid red 13 shows almost exclusively the $[\mathrm{M}-2 \mathrm{Na}+\mathrm{H}]^{-}$peak. These isomers differ in the position of one sulfonate group, which may affect the ease of loss of the sodium ions. However, since the Schweppe collection was assembled years ago from commercial dye sources, possibly some other factor is responsible for this difference.

It should be noted that these mass spectral peaks (for example, in Table 1) correspond to species like [M $\mathrm{Na}]^{-},[\mathrm{M}-2 \mathrm{Na}+\mathrm{H}]^{-},[\mathrm{M}-3 \mathrm{Na}+2 \mathrm{H}]^{-}$, etc., because the observed species in MALDI-TOF mass spectrometry are virtually always singly charged; the species formed in the MALDI plume gain or lose protons, and the surviving +1 or -1 ions are observed in the spectra [13].

Table 1 suggests that the usual ionization mechanism for acid dyes is loss of all sodium ions and, occasionally, loss of $-\mathrm{SO}_{3}$. For basic dyes (Table 2), ionization usually occurs by loss of chloride. However, careful scrutiny of such mass spectra possibly may reveal subtle differences that could be used as compound-specific fingerprints that would supplement the identification capability based on the strongest peaks. For example, Acid

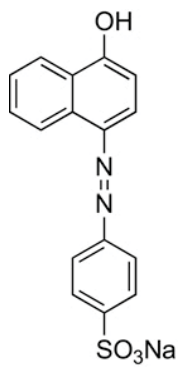

Structure 3

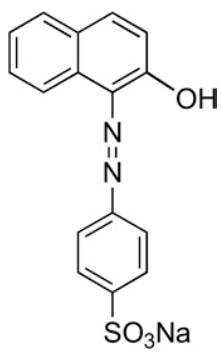

Structure 4



Structure 5 orange 20 (Structure 3), acid orange 7 (Structure 4), and acid orange 12 (Structure 5) are isomeric and, while sharing the same base peak, differ in their minor peaks (Table 1). We are investigating the possibility that post-source decay spectra may also reveal differences in the fragmentation patterns of isomeric dyes that will be useful for identification.

The MALDI-TOF spectra of certain dyes show evidence of clusters of two or more analyte molecules. We have observed this tendency in picric acid, acid yellow 24, and acid yellow 36 (Table 3). Mordant yellow 1 remarkably shows detectable sodiated clusters of as many as nine dye molecules. Since the dye concentrations in the Schweppe collection are not known, the extent to which concentration affects this clustering cannot be ascertained from our data.

\section{Sensitivity}

To assess the sensitivity of this method, we prepared successive dilutions of acid blue 83 (FisherBiotech brilliant blue R-250 electrophoresis grade, also known as Coomassie blue, MW $825.97 \mathrm{~g} / \mathrm{mol}$, Fair Lawn, NJ) in HPLC grade methanol; although acid blue 83 is not represented in the Schweppe library, it is included at the end of Table 1 . At a concentration of $10^{-7} \mathrm{~g} / \mathrm{mL}$ with $1 \mu \mathrm{L}$ of solution applied to the matrix layer on the target $\left(1.2 \times 10^{-13} \mathrm{~mol}\right.$ of dye on the target $)$, the negative ion spectrum showed a $[\mathrm{M}-\mathrm{Na}]^{-}$peak at $m / z$ 802.1 with signal-to-noise ratio of 660 . This level of sensitivity is more than sufficient to detect the dye extracted from single textile fibers. Figure $2 b$ shows the results of such an analysis from a Schweppe wool textile sample dyed with acid red 17. A few textile fibers, less material than would typically be available from a museum artifact, were extracted by hydrolysis as described in the Sample Preparation section. The mass spectral peak at $m / z 456.9\left([\mathrm{M}-2 \mathrm{Na}+\mathrm{H}]^{-}\right.$for acid red 17), obtained from $1 \mu \mathrm{L}$ of this extract, has a signal-tonoise ratio of 3196 .

\section{Precision and Accuracy}

We compared the precision and accuracy of the overlay versus the solvent-free sample preparation method by running 10 replicate spectra for each preparation method, each spectrum an average of 50 laser shots. We used a freshly purchased powder sample of the Schweppe dye mordant yellow 1 (Aldrich Alizarin yellow GG, MW $309.21 \mathrm{~g} / \mathrm{mol}$ ) for the solvent-free method and, for the overlay method, prepared a $5 \times$ $10^{-5} \mathrm{~g} / \mathrm{mL}$ solution of this dye in methanol. For the base peak $\left([\mathrm{M}-\mathrm{Na}]^{-}\right.$, exact mass $\left.286.0464 \mathrm{Da}\right)$, the solvent-free sample gave an average $m / z 286.20$ with a standard error for the 10 spectra of 0.15 , and the overlay sample gave an average $\mathrm{m} / \mathrm{z} 286.21$ with a standard error of 0.16. Our spectra for this dye from the Schweppe library sample itself (Table 1) gave $m / z 286.1$. 
Table 3. Negative ion dye spectra showing $\left[\mathrm{M}_{2}\right]$ species

\begin{tabular}{|c|c|c|c|}
\hline DYE & Nominal MW, Da & $m / z(\%)$ & $m / z(\%)$ \\
\hline Picric acid & 229 & $\begin{array}{c}228.4(100) \\
{[\mathrm{M}-\mathrm{H}]^{-}}\end{array}$ & $\begin{array}{c}478.9(85) \\
{\left[\mathrm{M}_{2}+\mathrm{Na}-\right.} \\
2 \mathrm{H}]^{-}\end{array}$ \\
\hline Acid yellow 24 & 256 & $\begin{array}{c}233.1(100) \\
{[\mathrm{M}-\mathrm{Na}]^{-}}\end{array}$ & $\begin{array}{c}489.1(100) \\
{\left[\mathrm{M}_{2}-\mathrm{Na}\right]^{-}}\end{array}$ \\
\hline Acid yellow 36 & 375 & $\begin{array}{c}352.5(100) \\
{[\mathrm{M}-\mathrm{Na}]^{-}}\end{array}$ & $\begin{array}{c}726.7(66) \\
{\left[\mathrm{M}_{2}-\mathrm{Na}\right]^{-}}\end{array}$ \\
\hline Mordant yellow 1 & 309 & $\begin{array}{c}286.1(100) \\
{[\mathrm{M}-\mathrm{Na}]^{-}}\end{array}$ & $\begin{array}{l}595.4(12) \\
{\left[\mathrm{M}_{2}-\mathrm{Na}\right]^{-}}\end{array}$ \\
\hline
\end{tabular}

These results suggest an uncertainty of \pm 0.2 in our $m / z$ values.

The standard error in base peak intensity for 10 spectra was $15 \%$ from the solvent-free sample and $7 \%$ for the overlay sample. As a measure of reliability for relative intensities, we also compared the ${ }^{13} \mathrm{C} /{ }^{12} \mathrm{C}$ isotope ratios from these mordant yellow 1 spectra. Compared with the computed ${ }^{13} \mathrm{C}$ relative abundance of $14.1 \%$ for the formula $\mathrm{C}_{13} \mathrm{H}_{8} \mathrm{~N}_{3} \mathrm{O}_{5}[\mathrm{M}-\mathrm{Na}]^{-}$, the solvent-free sample gave an average ${ }^{13} \mathrm{C}$ relative abundance of $14.3 \%$ with a standard error of $0.75 \%$, and the overlay sample gave an average relative abundance of $15.9 \%$ with a standard error of $0.68 \%$.

\section{Conclusions}

MALDI-TOF mass spectrometry affords a rapid, versatile, and reliable method for identifying dyes from femtomole samples. Sample preparation involves minimal handling and, therefore, minimal sample loss. Solvent-free vortex grinding is especially advantageous for analysis of insoluble pigments. The precision and accuracy of spectra from the solvent-free grinding method are comparable with those obtained with traditional overlay sample preparation, although the variability in absolute peak intensity appears to be greater with the solvent-free method. The comparison of positive and negative ion spectra provides structural information about the dye or pigment class and, in most cases, the identity of the substance. In favorable cases, the spectra can distinguish between isomers. This method has more than sufficient sensitivity for use with samples available for investigation of museum artifacts.

\section{Acknowledgments}

The authors gratefully acknowledge the financial support of the National Science Foundation (grant number: NSF-CHE-
0216268). They also thank a reviewer for pointing out the likelihood of observing dimers or larger clusters of dye molecules, and Dr. Kelsey D. Cook for many constructive suggestions about the manuscript.

\section{References}

1. Cohen, L. H.; Gusev, A. I. Small Molecule Analysis by MALDI Mass Spectrometry. Anal. Bioanal. Chem. 2002, 373, 571-586.

2. Soltzberg, L. J.; Patel, P. Small Molecule Matrix-assisted Laser Desorption/Ionization Time-of-Flight Mass Spectrometry Using a Polymer Matrix. Rapid Commun. Mass Spectrom. 2004, 18, 1455-1458.

3. Grim, D. M.; Siegel, J.; Allison, J. Evaluation of Laser Desorption Mass Spectrometry and UV Accelerating Aging of Dyes on Paper as Tools for the Evaluation of a Questioned Document. J. Forensic Sci 2002, 47, 1265-1273.

4. Grim, D. M.; Allison, J. Identification of Colorants as Used in Watercolor and Oil Paintings by UV Laser Desorption Mass Spectrometry. Int. J. Mass Spectrom. 2003, 222, 85-99.

5. Hanton, S. D.; Parees, D. M. Extending the Solvent-free MALDI Sample Preparation Method. J. Am. Soc. Mass Spectrom. 2005, 16, 90-93.

6. Trimpin, S.; Keune, S.; Rader, H. J.; Müllen, K. Solvent-Free MALDI-MS: Developmental Improvements in the Reliability and the Potential of MALDI in the Analysis of Synthetic Polymers and Giant Organic Molecules, and References Therein. J. Am. Soc. Mass Spectrom. 2006, 17, 661-671.

7. Schweppe Collection of Important Early Synthetic Dyes (Getty Conservation Institute, Los Angeles, CA). The collection consists of methanol solutions of 66 dyes assembled by the late Helmut Schweppe of BASF $\mathrm{GmbH}$, as well as fabric swatches dyed with these substances. The concentrations of the dye solutions comprising the Schweppe collection are not known.

8. Vermillion-Salsbury, R. L.; Hercules, D. M. 9-Aminoacridine as a Matrix for Negative Mode Matrix-Assisted Laser Desorption/Ionization. Rapid Commun. Mass Spectrom. 2002, 16, 1575-1581.

9. Ng, L.-K.; Lafontaine, P; Brazeau, L. Ballpoint Pen Inks: Characterization by Positive and Negative-Ion Electrospray Mass Spectrometry for the Forensic Examination of Writing Inks. J. Forensic Sci. 2002, 47, $1238-1247$.

10. From Pastel Box Formerly Belonging to Mary Cassatt (c. 1900-1910), Boston Museum of Fine Arts, Accession No. 1999.83 (Gift of Edith Smith).

11. Aldrich Handbook of Fine Chemicals, 2007-2008, p 1782.

12. Aldrich Handbook of Fine Chemicals, 2007-2008, p 769.

13. Karas, M.; Glückmann, M.; Schafer. J. Ionization in Matrix-assisted Laser Desorption/Ionization: Singly Charged Molecular Ions are the Lucky Survivors. J. Mass Spectrom. 2000, 35, 1-12. 